\title{
Estimativas dos emigrantes internacionais do Brasil entre 1995 e 2000: uma aplicação do método das razões intercensitárias de sobrevivência
}

\author{
Ricardo Alexandrino Garcia*
}

Dada à ausência de dados sobre movimentos populacionais no espaço e no tempo, há muito os demógrafos e estudiosos de população lançam mão de técnicas indiretas para a mensuração de saldos migratórios. Os últimos censos demográficos brasileiros contêm um notável conjunto de dados sobre movimentos populacionais que, se adequadamente trabalhados, podem proporcionar estimativas sobre importantes aspectos dos fluxos migratórios. Por outro lado, dados não diretamente ligados à migração, manipulados a partir de técnicas indiretas, permitem chegar à estimação de saldos migratórios. A geração de estimativas de fluxos migratórios internos e, mais recentemente, internacionais, por meio da combinação de técnicas diretas e indiretas, representa um desafio metodológico que vem sendo enfrentado por alguns demógrafos dedicados aos estudos de migração. Poucos estudos, contudo, têm se destinado ao desenvolvimento e aperfeiçoamento de métodos e técnicas direcionados à estimação de categorias analíticas, tais como saldos migratórios intercensitários, migração de retorno, migração por etapas, migração de passagem e emigração internacional. O principal objetivo deste trabalho é, portanto, oferecer estimativas da emigração internacional de brasileiros por sexo, idade e unidades da federação, referentes à segunda metade da última década do século por meio da técnica das Razões Intercensitárias de Sobrevivência (RIS).

Palavras-chave: Migração internacional. Técnicas indiretas de migração. Brasil.

\footnotetext{
* Doutor em demografia, professor adjunto do Departamento de Geografia do Instituto de Geociências da Universidade Federal de Minas Gerais - UFMG (alexandrinogarcia@gmail.com).
} 


\section{Introdução}

Os últimos censos demográficos brasileiros contêm um notável conjunto de dados sobre movimentos populacionais que, se adequadamente trabalhados, podem proporcionar estimativas sobre importantes aspectos dos fluxos migratórios. Por outro lado, dados não diretamente ligados à migração, manipulados a partir de técnicas indiretas, permitem chegar à estimação de saldos migratórios (CARVALHO, 1980). A geração de estimativas de fluxos migratórios internos e, mais recentemente, internacionais, por meio da combinação de técnicas diretas e indiretas, representa um desafio metodológico que vem sendo enfrentado por alguns demógrafos dedicados aos estudos de migração. Assim, diversos trabalhos investiram no desenvolvimento e aperfeiçoamento de métodos e técnicas direcionados à estimação de categorias analíticas, tais como saldos migratórios intercensitários, migração de retorno, migração por etapas, migração de passagem e emigração internacional (BRITO; GARCIA; CARVALHO, 2002).

$\mathrm{Na}$ ausência de dados sobre movimentos populacionais no espaço e no tempo, há muito os demógrafos e estudiosos de população lançam mão de técnicas indiretas para a mensuração de saldos migratórios, sendo que uma delas é a chamada Técnica das Razões Intercensitárias de Sobrevivência (RIS). Um bom exemplo de sua aplicabilidade pode ser encontrado no trabalho de Carvalho e Fernandes, que, em 1996, estimaram os saldos migratórios rurais e urbanos dos Estados e Regiões do Brasil, referentes às décadas de 1960 e 1970. Os autores apontam, no entanto, que um dos pressupostos da técnica da RIS é a de que o saldo migratório para o total do país seja nulo durante o período de referência, o que inviabilizaria seu emprego para estimação de saldos migratórios internacionais (CARVALHO; FERNANDES, 1996). Naquele mesmo ano, entretanto, Carvalho publicou um estudo pioneiro sobre estimativas dos saldos dos fluxos migratórios internacionais da década de 1980, com base em uma adaptação da técnica, constatando que o Brasil, de país receptor, passou a expulsor de população (CARAVALHO, 1996). No ano seguinte, Beltrão e Camarano (1997), por meio de outros métodos, chegaram à mesma conclusão.

Uma revisão desta adaptação proposta na técnica da RIS foi oferecida por Carvalho e Rigotti (1998), que formalizaram o procedimento de se estimarem saldos migratórios decenais e quinquenais na presença de fluxos migratórios internacionais. No ano seguinte, Rigotti (1999) estimou, indiretamente, os saldos migratórios de São Paulo e Minas Gerais para a década de 1980.

A primeira estimativa de emigração internacional, combinando técnicas diretas e indiretas de migração, ocorreu em 2000, com o trabalho liderado por Carvalho que, juntamente com seus alunos de pós-graduação, publicou o artigo "Sinuosos caminhos para estimação dos emigrantes internacionais de 1986/1991 e de 1991/1996 e dos saldos migratórios dos quinquênios entre 1981 e 1996 das Unidades da Federação brasileira", no qual são estimados os emigrantes internacionais por sexo e idade de Minas Gerais, da Região Sudeste e do Brasil (CARVALHO et al., 2000a). Os autores publicaram ainda um 
artigo sobre as estimativas dos saldos migratórios e emigrantes internacionais do Paraná (CARVALHO et al., 2000b) e outro sobre a VIII Região de Planejamento de Minas Gerais: Rio Doce (CARVALHO et al., 2000c); por fim, em 2001, essa mesma equipe participou do livro Migrações internacionais contribuições para políticas, da Comissão Nacional de População e Desenvolvimento (CNPD), com um capítulo sobre estimativas dos emigrantes internacionais do Brasil, nos quinquênios 1986/1991 e 1991/1996.

Diante dos avanços obtidos, a partir de 2000, na aplicação da técnica da RIS, Carvalho e Garcia, retomando o trabalho de Carvalho e Fernandes (1996), formalizaram e publicaram uma série de estimativas indiretas sobre saldos e taxas migratórias quinquenais, entre 1960 e 1990, e volume da emigração internacional segundo sexo, idade, situação de domicílio e Estado (CARVALHO; GARCIA, 2002). Entre 2002 e 2003, duas teses de doutorado empregaram os procedimentos formalizados por estes autores (SOARES, 2002; MAGALHÃES, 2003) e, em 2005, baseado no trabalho de Carvalho e Garcia (2002), Garcia apresentou as estimativas dos emigrantes internacionais brasileiros da segunda metade da década de 1980, durante a 25a Conferência Internacional de População (GARCIA, 2005).

Com a divulgação dos dados do Censo Demográfico de 2000, constatou-se que outro pressuposto para aplicação da técnica foi quebrado: a melhora significativa do índice de cobertura censitária em relação aos censos anteriores. Carvalho e Campos (2006), contudo, lançando mão das Pesquisas de Avaliação da Cobertura da Coleta dos Censos de 1991 e 2000, chegaram a uma estimativa negativa de saldo migratório internacional de 550 mil pessoas, correspondente a uma perda líquida de 294 mil homens e de 256 mil mulheres, entre aqueles com dez anos ou mais de idade, em 2000 (CARVALHO; CAMPOS, 2006).

Com base nas estimativas do saldo migratório decenal para a década de 1990 de Carvalho e Campos (2007) e retomando a técnica da RIS, Garcia (2010) propôs estimar o volume da emigração internacional do Brasil e Regiões, por meio de métodos iterativos, capazes de calcular o índice de variação de cobertura censitária para cada região, contornando, assim, a quebra do pressuposto observado nas informações do Censo de 2000. Ocorre que, tanto no trabalho de Carvalho e Campos (2007) quanto no de Garcia (2010), observa-se um nítido problema na estrutura etária das estimativas, derivado do fato de que a variação da cobertura censitária não é constante por sexo e idade, tal como os autores supuseram.

Este artigo tem por objetivo estimar de forma consistente o volume da emigração internacional do Brasil e Regiões por sexo e grupos etários, entre 1995 e 2000. Para tanto, foram gerados, iterativamente, índices específicos de variação de cobertura censitária entre 1991 e 2000, o que possibilitou a aplicação da técnica da RIS para o cálculo dessas estimativas. Pretende-se, portanto, oferecer, por um lado, uma contribuição original para o avanço das técnicas indiretas de migração e, por outro, estimativas inéditas de saldos, taxas e volumes migratórios do país, na segunda metade da década de 1990.

Considerando os objetivos deste trabalho, serão descritos os procedimentos para se estimar a migração interna e internacional, bem como os saldos e taxas líquidas quinquenais, por sexo e idade, segundo os Estados brasileiros. Além disso, serão abordados 
os procedimentos para se estimar, no quinquênio 1995-2000, o número de emigrantes internacionais por sexo e idade, para cada Estado.

Tanto os procedimentos metodológicos quanto as estimativas apresentadas referem-se a migrantes de data fixa. Imigrante de data fixa é o indivíduo que, no início do período em análise, residia em outra região e, no final, mora na região em questão. Emigrante de data fixa é a pessoa que residia na região em estudo, no início do período, e reside em outra, no final.

\section{Procedimentos metodológicos}

\section{Saldo migratório e taxa líquida de migração}

O saldo migratório (SM) constitui, para determinado período, o resultado da diferença entre imigrantes e emigrantes de data fixa e leva em consideração os efeitos indiretos do fluxo. "O SM mede a contribuição das migrações ao crescimento populacional do período" (CARVALHO; RIGOTTI, 1998).

Já a taxa líquida de migração (TLM) pode ser construída de duas formas: pela razão entre o SM e a população esperada fechada no final do período ou pela razão entre o SM e a população observada, também no final do período. Neste caso, a TLM consiste na "proporção da população observada no segundo censo resultante do processo migratório, quando a taxa for positiva, e a proporção em que a população seria acrescida na ausência de migração, se negativa" (CARVALHO; RIGOTTI, 1998). Se o denominador for a população esperada fechada no final do período, a TLM corresponde à proporção em que a população fechada foi acrescida, se positiva, ou diminuída, se negativa, como consequência dos fluxos migratórios do período.

OSM intercensitário, quando estimado a partir de técnica indireta, é obtido por resíduo, ou seja, pela diferença, no segundo censo, entre a população observada e a esperada (fechada).

Dado um período intercensitário de $n$ anos, a população esperada na região $j$, no segundo censo, no grupo etário $\mathrm{x}+\mathrm{n}, \mathrm{x}+\mathrm{n}+\mathrm{m}$, corresponde à população observada no primeiro censo, no grupo etário $\mathrm{x}, \mathrm{x}+\mathrm{m}$, multiplicada pela relação de sobrevivência do período. Então:

$$
{ }_{m} P_{x+n, e s p}^{j, n}={ }_{m} P_{x, o b}^{j, o *}{ }_{m}^{n} S_{x}^{j}
$$

onde:

${ }_{m} P_{x+n, \text { esp }}^{j, n}=$ população esperada (fechada) na região $j$, do grupo etário $\mathrm{x}+\mathrm{n}, \mathrm{x}+\mathrm{n}+\mathrm{m}$, no segundo censo (ano n);

${ }_{m} P_{x, o b}^{j, o}=$ população observada na região $j$, no primeiro censo (ano 0), no grupo etário $\mathrm{x}, \mathrm{x}+\mathrm{m}$; ${ }_{m}^{n} S_{x}^{j}=$ relação de sobrevivência do grupo etário $\mathrm{x}, \mathrm{x}+\mathrm{m}$, do ano 0 , durante o período de $n$ anos, da região $j$.

\footnotetext{
${ }^{1}$ Os procedimentos metodológicos aqui arrolados foram adaptados do artigo "The estimates of the Brazilian international net migration and the Brazilian emigrants, based on the method of inter-census survival ratio (ISR)”, de Garcia (2005), disponivel em: 〈http://iussp2005. princeton.edu/download. aspx?submissionld=51537 `.
} 
O SM é dado pela seguinte expressão:

$$
{ }_{m}^{n} S M_{x+n}^{j, n}={ }_{m} P_{x+n, o b}^{j, n}-{ }_{m} P_{x+n, e s p}^{j, n}
$$

onde:

${ }_{m}^{n} S M_{x+n}^{j, n}=\mathrm{SM}$ do período de $n$ anos, no grupo etário $\mathrm{x}+\mathrm{n}, \mathrm{x}+\mathrm{n}+\mathrm{m}$, ao final do período (no ano $n$ );

${ }_{m} P_{x+n, o b}^{j, n}=$ população observada na região, no primeiro censo (ano $n$ ), no grupo etário $\mathrm{x}+\mathrm{n}$.

Já a taxa líquida de migração do grupo etário, ao final do período, $\mathrm{x}+\mathrm{n}, \mathrm{x}+\mathrm{n}+\mathrm{m}\left({ }_{m}^{n} T L M_{x+n}^{j, n}\right)$ é dada por uma das seguintes equações:

$$
\begin{aligned}
& { }_{m}^{n} T L M_{x+n}^{j, n}=\frac{{ }_{m}^{n} S M_{x+n}^{j, n}}{{ }_{m} P_{x+n, o b}^{j, n} \mid} \\
& { }_{m}^{n} T L M_{x+n}^{j, n}=\frac{{ }_{m}^{n} S M_{x+n}^{j, n}}{{ }_{m} P_{x+n, e s p}^{j, n}}
\end{aligned}
$$

A TLM corresponde ao quociente entre o saldo migratório $\left({ }_{m}^{n} S M_{x+n}^{j, n}\right)$ e a população ao final do período, observada $\left({ }_{m} P_{x+n, o b}^{j, n}\right)$, ou esperada $\left({ }_{m} P_{x+n, \text { esp }}^{j, n}\right)$ (CARVALHO; RIGOTTI, 1998).

Tanto nos SM quanto nas TLM, de determinado período, estão contidos os migrantes de data fixa da região, isto é, os que lá não residiam no início do período e residem ao final (imigrantes) e os que lá residiam no início do período e residem fora da região ao final (emigrantes).

\section{A técnica das razões intercensitárias de sobrevivência decenais}

Devido a erros de declaração de idade e à deficiência de cobertura censitária, se a população do país puder ser considerada fechada, é aconselhável o uso das razões intercensitárias de sobrevivência (RIS) do país, ajustadas ao nível de mortalidade da região em estudo, em vez de utilizar, como poderia parecer à primeira vista mais apropriado, as relações de sobrevivência retiradas de tabelas de mortalidade da região (CARVALHO; RIGOTTI, 1998). A partir das RIS do país, estimam-se as RIS da região, isto é, suas razões intercensitárias de sobrevivência, caso tivesse população fechada. Para um período intercensitário de dez anos ter-se-ia:

$$
{ }_{5}^{10} \overline{R I S}_{x}^{j}={ }_{5}^{10} R I S_{x}^{B R,} * \frac{\frac{{ }_{5} L_{x+10}^{j}}{{ }_{5} L_{x}^{j}}}{\frac{{ }_{5} L_{x+10}^{B R}}{{ }_{5} L_{x}^{B R}}}
$$

onde:

${ }_{5}^{10} \overline{R I S}_{x}^{j}=$ razão intercensitária de sobrevivência estimada da população fechada da região j, referente ao decênio em questão, do grupo etário x, $\mathrm{x}+5$; 
${ }_{5}^{10} R I S_{x}^{B R,}=$ razão intercensitária de sobrevivência decenal observada do país, do grupo etário $\mathrm{x}, \mathrm{x}+5$;

$\frac{{ }_{5} L_{x+10}^{j}}{{ }_{5} L_{x}^{j}}$ e $\frac{{ }_{5} L_{x+10}^{B R,}}{{ }_{5} L_{x}^{B R}}=$ relações de sobrevivência decenal, do grupo etário $\mathrm{x}, \mathrm{x}+5$, das tabelas de mortalidade, referentes ao decênio em questão, da região e do país, respectivamente.

Assim, a população esperada da região $j$, em determinado grupo etário, ao final do decênio, quando se consideram os grupos etários a partir de dez anos, é o produto da população observada no início do período pelas RIS estimadas para essa mesma região. É o que põe em evidência, para a década de 1960, por exemplo, a seguinte equação:

$$
{ }_{5} P_{x+10, e s p}^{j, 70}={ }_{5} P_{x, o b}^{j, 60 *}{ }_{5}^{10} \overline{R I S}_{x}^{j, 60 / 70}
$$

O saldo migratório decenal das pessoas com idade superior a dez anos, resultante da diferença entre a população observada na região j, em 1970, e a população esperada, nesse mesmo ano, na mesma região, deve ser entendido como a contribuição dos fluxos migratórios do período 1960-1970 para o (de)crescimento populacional da região.

Obtêm-se os SM dos grupos etários de 0-4 e 5-9 anos, no final do decênio, multiplicandose a soma dos SM da região, referentes às mulheres em idade reprodutiva, pelas razões crianças/mulher observadas na população da região, sendo uma razão correspondente às crianças de 0-4 anos e a outra às de 5-9 anos (LEE, 1957).

\section{O problema da aplicação da técnica das RIS nas décadas de 1980 e 1990}

A aplicação do método das RIS exige o pressuposto de que a população do país mantevese fechada no período, o que não ocorreu no caso brasileiro na década de 1980 (a emigração internacional foi significativa nesse período).

Carvalho (1996) propõe que se estimem as RIS da população fechada do Brasil dos anos 1980 a partir daquelas observadas na década de 1970, quando o país tinha população praticamente fechada. Para tal, há de se ajustá-las aos níveis de mortalidade da década de 1980 e pressupor que as variações no padrão de erros de declaração de idade e no grau de cobertura censitária entre os Censos de 1980 e 1991 foram as mesmas ocorridas entre os Censos de 1970 e 1980.

$$
{ }_{5} \overline{R I S}_{x}^{B R, 80 / 90}={ }_{5} R I S_{x}^{B R, 70 / 80} \cdot \frac{\frac{{ }_{5} L_{x}^{B R, 80 / 90}}{{ }_{5}^{B R, 80 / 90}}}{\frac{{ }_{5} L_{x+10}^{B R, 70 / 80}}{{ }_{5} L_{x}^{B R, 70 / 80}}}
$$

onde:

${ }_{5} \overline{R I S}_{x}^{B R, 80 / 90}=$ RIS estimada da população fechada do Brasil, período 1980-1990, grupo etário $\mathrm{x}, \mathrm{x}+5$;

${ }_{5} R I S_{x}^{B R, 70 / 80}=$ RIS observada do Brasil, período 1970-1980, grupo etário x, $\mathrm{x}+5$; 
$\frac{\frac{{ }_{5} L_{x+10}^{B R, 80 / 90}}{{ }_{5} L_{x}^{B R, 80 / 90}}}{{ }_{5} L_{x+10}^{B R, 70 / 80}}$ as décadas de 1970 e 1980.

As RIS dos anos 1980 estimadas da região j, necessárias para a estimação de seus SM, serão dadas por (CARVALHO; RIGOTTI, 1998):

$$
{ }_{5}^{10} \overline{R I S}_{x}^{j, 80 / 90}={ }_{5}^{10} R I S_{x}^{B R, 70 / 80} * \frac{\frac{{ }_{5} L_{x+10}^{j, 80 / 90}}{{ }_{5}^{j, 80 / 90}}}{\frac{{ }_{5} L_{x+10}^{B R, 70 / 80}}{{ }_{5} L_{x}^{B R, 70 / 80}}}
$$

Esse procedimento pressupõe, entretanto, uma relação constante, em escala nacional e regional, entre o grau de cobertura dos Censos Demográficos ao longo do tempo e que o grau de cobertura censitária, em um dado Censo, seja único, independentemente de sexo, idade ou região. Com a finalidade de flexibilizar esses pressupostos, tornando, assim, o modelo mais realista, propõe-se ajustar as RIS estimada dos anos 1990 da região j por meio de um multiplicador K que, estimado iterativamente, corrigirá, por sexo, idade e região, a variação longitudinal entre os graus de cobertura dos Censos Demográficos. Para tanto, fazse necessário que alguns parâmetros sejam estabelecidos a priori, uma vez que o método iterativo estimará os valores de K em função desses parâmetros. O primeiro diz respeito ao nível da migração internacional como um todo e o segundo refere-se à estrutura etária dos emigrantes internacionais da década de 1990, por sexo, idade e região. Admitiu-se, então, o valor de -550 mil para o saldo migratório internacional brasileiro no período de referência ${ }^{2}$ e, como proxy da estrutura etária dos emigrantes internacionais, foi utilizada a estrutura observada dos imigrantes de data fixa retornados ao Brasil entre 1995 e 2000, segundo Estado. ${ }^{3}$ Assim, tem-se:

$$
{ }_{5}^{10} \overline{R I S}_{x}^{j, 90 / 00}={ }_{5}^{10} R I S_{x}^{B R, 70 / 80} * \frac{\frac{{ }_{5} L_{x+10}^{j, 90 / 00}}{L_{x}^{j, 90 / 00}}}{\frac{{ }_{5} L_{x+10}^{B R, 70 / 80}}{{ }_{5} L_{x}^{B R, 70 / 80}}} *{ }_{5}^{10} K_{x}^{j, 90 / 00}
$$

onde:

${ }_{5}^{10} K_{x}^{j, 90 / 00}$ é o fator de correção da RIS, estimado iterativamente pelo método Newton-Raphson, necessário quando se deseja considerar o grau de cobertura censitária independente no tempo e no espaço.

\footnotetext{
${ }^{2}$ Carvalho e Campos (2006) estimaram que, durante a década de 1990, a migração internacional brasileira teve um saldo negativo de 550 mil pessoas.

${ }^{3}$ Essa escolha deveu-se ao fato de que esses imigrantes efetivamente participaram, no período de referência, do processo de saída do país, ou seja, da emigração internacional, cuja mensuração é um dos principais objetivos desse estudo.
} 
O método de Newton-Raphson, ou o método de Newton, é uma técnica poderosa para se resolverem equações numericamente. Foi proposto por Isaac Newton em 1669, John Wallis publicou-o em 1685 e Joseph Raphson (1648-1715) apresentou sua versão definitiva em 1690. Tal como outros métodos de aproximações sucessivas do cálculo diferencial, ele é baseado na ideia simples de aproximação linear, cujo valor almejado, ou seja, a raiz da função, não está entre intervalos predefinidos. Na verdade, apenas uma estimativa inicial desse valor é necessária para que o processo iterativo comece a encontrar o valor que satisfaça o modelo. Este método, portanto, se enquadra na categoria de métodos abertos, cuja convergência não é garantida a priori, mas sua implementação em planilhas eletrônicas é relativamente simples e de fácil operação (BILLO, 2001, p. 193-207).

\section{Como obter estimativas quinquenais de SM e TLM a partir das RIS decenais}

Para se estimarem os saldos migratórios quinquenais, quando o intervalo entre os censos for de dez anos, é necessário estimar tanto a população residente quanto a população esperada (fechada) da região $j$, no meio do período intercensitário. Para isso, aplicou-se, em ambos os casos, o método de relação de coortes, proposto por Duchesne (1989). ${ }^{4}$

Segundo Duchesne, dadas as razões decenais de sobrevivência observadas de dois grupos etários quinquenais consecutivos, ${ }_{5}^{10} S_{x}$ e ${ }_{5}^{10} S_{x+5}$, a razão de sobrevivência quinquenal comum, ${ }_{5}^{5} S_{x+5}$, implícita nas duas razões decenais, será dada, aproximadamente, pela média das raízes quadradas delas. ${ }^{5}$ Ou seja:

$$
{ }_{5}^{5} S_{x+5} \cong \frac{\sqrt{{ }_{5}^{10} S_{x}}+\sqrt{{ }_{5}^{10} S_{x+5}}}{2}
$$

As relações de coortes observadas, aqui denominadas razões decenais de sobrevivência observadas, que fazem parte do algoritmo proposto por Duchesne, referem-se a populações

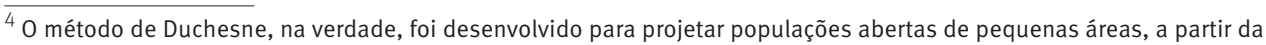
projeção, pelo método das componentes, da população da área maior composta pelas pequenas áreas, cujas populações estão sendo objeto de projeção. Trata-se, neste trabalho, de uma adaptação da proposta original do autor. Como exemplo de aplicação do método em projeção populacional de pequenas áreas no Brasil, veja: Waldvogel (1998).

${ }_{5}^{5} S_{x}={ }_{5}^{5} S_{x} \cdot{ }_{5}^{5} S_{x+5}$

${ }_{5}^{10} S_{x+5}={ }_{5}^{5} S_{x+5} \cdot{ }_{5}^{5} S_{x+10}$

$\sqrt{{ }_{5}^{10} S_{x}}=\sqrt{{ }_{5}^{5} S_{x} \cdot{ }_{5}^{5} S_{x+5}} \cong{ }_{5}^{5} S_{x+2,5}$

$\sqrt{{ }_{5}^{10} S_{x+5}}=\sqrt{{ }_{5}^{5} S_{x+5} \cdot{ }_{5}^{5} S_{x+10}} \cong{ }_{5}^{5} S_{x+7,5}$

$\frac{\sqrt{{ }_{5}^{10} S_{x}}+\sqrt{{ }_{5}^{10} S_{x+5}}}{2} \cong \frac{{ }_{5}^{5} S_{x+2,5}+{ }_{5}^{5} S_{x+7,5}}{2} \cong={ }_{5}^{5} S_{x} \cdot{ }_{5}^{5} S_{x+5}$

Para o grupo aberto (último grupo etário) ${ }_{+}^{5} S_{x}$

${ }_{+}^{5} S_{x} \cong \frac{\sqrt{{ }_{+}^{10} S_{x-5}}+\sqrt{{ }_{+}^{10} S_{x}}}{2}$
} 
abertas. Logo, nelas estão incluídos os efeitos de mortalidade, dos fluxos migratórios, dos erros de declaração de idade e das mudanças de grau de cobertura entre os dois levantamentos censitários. A aplicação do mesmo algoritmo a populações fechadas deveria, em princípio, produzir melhores estimativas, por não estarem influenciadas pelos fluxos migratórios. Esse procedimento, entretanto, é incapaz de corrigir efeitos abruptos no comportamento do estoque populacional por coorte no período intercensitário, ou seja, o modelo é incapaz de romper o pressuposto de linearidade das razões de sobrevivência.

Neste trabalho, adota-se o algoritmo de Duchesne com duas finalidades diferentes: estimação das relações quinquenais de coorte da população aberta, com o objetivo de obter a população residente da região no final do primeiro quinquênio da década; e desagregação de cada RIS decenal estimada da população fechada da região (equação 5) em duas RIS, uma referente ao primeiro quinquênio do decênio e a outra ao segundo quinquênio.

\section{Estimação das relações quinquenais de coorte da população aberta}

Com o objetivo de obter a população residente da região no final do primeiro quinquênio da década, propõe-se a equação a seguir, para a estimação das relações quinquenais de coorte da população aberta:

$$
{ }_{5}^{5} R C_{x+5}^{j}=\frac{\sqrt{{ }_{5}^{10} R C_{x}^{j}}+\sqrt{{ }_{5}^{10} R C_{x+5}^{j}}}{2}
$$

onde:

${ }_{5}^{5} R C_{x+5}^{j}=$ relação de coorte quinquenal estimada da população aberta, grupo etário inicial $x+5, x+10$, da região $j$;

${ }_{5}^{10} R C_{x}^{j}=$ relação de coorte decenal observada, grupo etário inicial $\mathrm{x}, \mathrm{x}+5$, da região $j$; ${ }_{5}^{10} R C_{x+5}^{j}=$ relação de coorte decenal observada, grupo etário inicial $x+5, x+10$, da região $j$.

No caso das relações quinquenais de coorte estimadas, todas referem-se ao primeiro quinquênio do decênio.

A população residente estimada, com dez ou mais anos de idade, no meio da década, é o produto da população aí observada com cinco ou mais anos, no início do período, pelas relações de coorte estimadas para o quinquênio. ${ }^{6}$

$$
{ }_{5} \bar{P}_{x+10, r}^{j, 5}={ }_{5} P_{x+5, o b}^{j, 0} \cdot{ }_{5}^{5} R C_{x+5}^{j}
$$

onde:

${ }_{5} \bar{P}_{x+10, r}^{j, 5}=$ população estimada residente na região $j$, no ano 5 , grupo etário $x+10, x+15$

${ }_{5} P_{x+5, o b}^{j, 0}=$ população observada na região $j$, no ano 0 , grupo etário $x+5, x+10$.

Para o grupo etário de 0 a 4 anos, no início do quinquênio, estima-se indiretamente a relação de coorte quinquenal, dividindo-se a relação decenal observada, do grupo inicial de 0 a 4 anos, pela relação quinquenal estimada, por meio do algoritmo, do grupo de 5 a 9 anos.

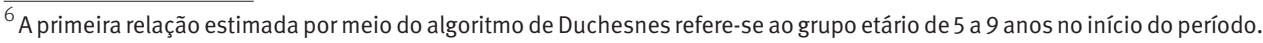


A população residente estimada de 0 a 4 anos no meio do decênio foi obtida aplicandose, às mulheres residentes (estimadas) em idade reprodutiva, a média das razões crianças/ mulher observadas no início e no final do decênio.

\section{Desagregação da RIS decenal da população fechada}

A desagregação da RIS decenal estimada da população fechada da região em duas, uma referente ao primeiro quinquênio do decênio e a outra ao segundo quinquênio, pode ser estimada segundo as equações abaixo:

$$
\begin{aligned}
& { }_{5}^{5} \overline{R I S}_{x+5}^{j, I}=\frac{\sqrt{{ }_{5}^{10} \overline{R I S}_{x}^{j}}+\sqrt{{ }_{5}^{10} \overline{R I S}_{x+5}^{j}}}{2} \\
& { }_{5}^{5} \overline{R I S}_{x+10}^{j, I I}=\frac{{ }_{5}^{10} \overline{R I S}_{x+5}^{j}}{{ }_{5}^{5} \overline{R I S}_{x+5}^{j, I}}
\end{aligned}
$$

onde:

${ }_{5}^{5} \overline{R I S} S_{x+5}^{j, I}=R I S$ estimada da população fechada, no primeiro quinquênio, grupo etário inicial $\mathrm{x}+5, \mathrm{x}+10$, região $j$;

${ }_{5}^{5} \overline{R I S}{ }_{x+10}^{j, I I}=R I S$ estimada do segundo quinquênio da população fechada, com idade $\mathrm{x}+10$, $x+15$ no início do quinquênio, região $j$.

\section{Estimação do SM quinquenais}

Multiplicando-se as RIS estimadas do primeiro quinquênio (equação 13) pela população observada no início do período, obtém-se a população esperada (fechada) estimada ao final do quinquênio, para os grupos etários com idade igual ou superior a dez anos. ${ }^{8}$ Subtraída esta população, em cada grupo etário, daquela residente estimada (equação 12), obtém-se o SM do primeiro quinquênio.

$$
\begin{aligned}
{ }_{5} \bar{P}_{x+10, \text { esp }}^{j, 5} & ={ }_{5} P_{x+5, o b}^{j, 0} \cdot{ }_{5}^{5} \overline{R I S}_{x+5}^{j, I} \\
{ }_{5} \overline{S M}_{x+10}^{j, I} & ={ }_{5} \bar{P}_{x+10, r}^{j, 5}-{ }_{5} \bar{P}_{x+10, \text { esp }}^{j, 5}
\end{aligned}
$$

onde:

${ }_{5} \bar{P}_{x+10, \text { esp }}^{j, 5}=$ população esperada (fechada) da região $j$, no ano 5 , grupo etário $\mathrm{x}+10, \mathrm{x}+15$; ${ }_{5} \overline{S M}_{x+10, \text { esp }}^{j, I}=$ SM estimado do primeiro quinquênio da região $j$, grupo etário (ao final do quinquênio) $x+10, x+15$.

Para obter a população residente no grupo etário de 5 a 9 anos, ao final do primeiro quinquênio, e o correspondente SM, é necessária uma estimativa da RIS do grupo etário de 0 a 4 anos $\left({ }_{5}^{5} \overline{R I S}_{0}^{j, I}\right)$.

\footnotetext{
7 Há de se observar que, para uma mesma coorte, a razão decenal de sobrevivência é igual ao produto das razões de sobrevivência nos dois quinquênios que compõem o decênio. Assim: ${ }_{5}^{10} \frac{{ }_{R}}{R I S_{x+5}^{j}}={ }_{5}^{5} \frac{a}{R I S} S_{x+5}^{j, I} *{ }_{5}^{5} \frac{T}{R I S}{ }_{x+10}^{j, I}$. A primeira RIS estimada do segundo quinquênio, por meio desta equação, é a do grupo etário inicial de 10 a 14 anos.

${ }^{8} \mathrm{~A}$ primeira RIS do primeiro quinquênio, estimada por meio do algoritmo de Duchesne, corresponde à do grupo etário inicial de 5 a 9 anos.
} 
Para tal, pressupõe-se que a ${ }_{5}^{5} \overline{R I S}_{5}^{j, I I}$ seja igual a ${ }_{5}^{5} \overline{R I S}_{5}^{j, I}$, já estimada. Deve-se lembrar que não é possível estimar ${ }_{5} \overline{R I S}_{5}^{j, I I}$ pela equação (12). Aceito o pressuposto, terá que:

$$
{ }_{5}^{5} \overline{R I S}_{0}^{j, I}=\frac{{ }_{5}^{10} \overline{R I S}_{0}^{j}}{{ }_{5}^{5} \overline{R I S}_{5}^{j, I}}
$$

O SM do primeiro quinquênio no grupo etário de 0 a 4 anos é obtido mediante o mesmo procedimento adotado para se estimar a população residente de 0 a 4 anos ao final do quinquênio, isto é, aplicando-se a razão crianças/mulher à soma do SM das mulheres em idade reprodutiva.

Para a obtenção dos SM do segundo quinquênio, estima-se, para os grupos etários acima de cinco anos, a população esperada (fechada) ao final do quinquênio. ${ }^{9}$ Para tal, multiplica-se, em cada grupo etário, a população residente, já estimada (equação 12), no final do primeiro quinquênio, pelas RIS estimadas do segundo quinquênio ${ }^{10}$ (equação 14).

$$
{ }_{5} \bar{P}_{x+5, \text { esp }}^{j, 0(5-10)}={ }_{5} \bar{P}_{x, r}^{j, 5} \cdot{ }_{5} R I S_{x}^{j, I I}
$$

onde:

${ }_{5} \bar{P}_{x+5, \text { esp }}^{j, 0(5-10)}=$ população esperada (fechada entre os anos 5 e 10) na região $j$, no ano 10 , grupo etário $x+5, x+10$.

Os SM do segundo quinquênio serão dados por:

$$
{ }_{5} \overline{S M}_{x+5}^{j, I I}={ }_{5} P_{x+5, o b}^{j, 10}-{ }_{5} \bar{P}_{x+5, \text { esp }}^{j, 10(5-10)}
$$

onde:

${ }_{5} P_{x+5, o b}^{j, 10}=$ população observada na região $j$, no ano 10 , grupo etário $x+5, x+10$.

O SM quinquenal do grupo etário de 0 a 4 anos, no final do período, é obtido pela aplicação da relação criança/mulher observada, ao final do decênio, à soma dos SM das mulheres em idade reprodutiva.

Tais procedimentos produzem boas estimativas quinquenais de SM e de TLM, que se referem, porém, ao resultado líquido das trocas populacionais, entre duas datas fixas, da região em estudo com as demais regiões do país e com o exterior.

\footnotetext{
${ }_{9}^{9}$ A população fechada ao final do decênio é diferente da fechada ao final do segundo quinquênio. No primeiro caso, mantém-se fechada durante todo o decênio. No segundo caso, é a população residente no início do segundo quinquênio que se mantém fechada.

${ }^{10}$ Como para o segundo quinquênio a equação (14) só fornece estimativas de RIS a partir da idade de dez anos, adota-se, para os grupos etários 0 a 4 e 5 a 9 anos, o pressuposto de que suas RIS são, respectivamente, as mesmas, já estimadas, do primeiro quinquênio. Ou seja:$$
\begin{gathered}
{ }_{5}^{5} \overline{R I S}_{0}^{j, I I}={ }_{5} \overline{R I S}_{O}^{j, I} \\
{ }_{5} \overline{R I S}_{5}^{j, I I}={ }_{5}^{5} \overline{R I S}_{5}^{j, I}
\end{gathered}
$$ 


\section{Estimação dos emigrantes internacionais do quinquênio 1995-2000}

Para estimar os emigrantes internacionais do período 1995-2000, o primeiro passo consiste em extrair, do Censo de 2000, o número de imigrantes intra e internacionais e o número de emigrantes intranacionais desse período, referentes a determinada unidade espacial. Em seguida, do saldo migratório estimado para o segundo quinquênio, ${ }^{11}$ dessa mesma unidade espacial, devem ser excluídas a participação dos emigrantes intranacionais e a dos imigrantes intra e internacionais, mensurados anteriormente a partir do quesito diretamente ligado ao tema no censo (migração de data fixa), para se chegar ao número aproximado de emigrantes internacionais do período 1995-2000. Isso se expressa formalmente da seguinte maneira:

$$
\begin{aligned}
& { }_{5} S M_{x}^{j, I I}={ }_{5} I_{x, \text { int }}^{j, I I}+{ }_{5} I_{x, \text { dom }}^{j, I I}-{ }_{5} E_{x, \text { int }}^{j, I I}-{ }_{5} E_{x, \text { dom }}^{j, I I} \\
& { }_{5} E_{x, \text { int }}^{j, I I}={ }_{5} I_{x, \text { int }}^{j, I I}+{ }_{5} I_{x, \text { dom }}^{j, I I}-{ }_{5} E_{x, \text { dom }}^{j, I I}-{ }_{5} S M_{x}^{j, I I}
\end{aligned}
$$

onde:

${ }_{5} S M_{x}^{j, I I}=$ saldo migratório da região, relativo ao mesmo quinquênio;

${ }_{5} E_{x, \text { int }}^{j, I I}=$ emigrantes internacionais, data fixa, do quinquênio 1985-1990;

${ }_{5} I_{x, \text { int }}^{j, I I}=$ imigrantes internacionais, data fixa, do período 1995-2000;

${ }_{5} I_{x, \text { dom }}^{j, I I}=$ imigrantes, data fixa, do período 1995-2000, cuja origem corresponde a outros locais do Brasil;

${ }_{5} E_{x, \text { dom }}^{j, I}=$ emigrantes, data fixa, no segundo quinquênio, cujo destino corresponde a outros locais do Brasil.

O SM internacional do quinquênio será dado por:

$$
{ }_{5} S M_{x, \text { int }}^{j, I I}={ }_{x} I_{x, \text { int }}^{j, I I}-{ }_{5} \bar{E}_{x, \text { int }}^{j, I I}
$$

\section{Algumas observações para o bom entendimento dos resultados apresentados}

Os SM decenais não são a simples soma dos SM dos quinquênios que compõem cada decênio. Resultam da soma do saldo do segundo quinquênio com os sobreviventes do saldo migratório do primeiro quinquênio (CARVALHO; RIGOTTI, 1998), como registra a seguinte expressão:

$$
{ }_{5}^{10} S M_{x+10}^{j, d}={ }_{5}^{5} S M_{x+5}^{j, I} \star{ }_{5}^{5} \overline{R I S}_{x+5}^{j, I I}+{ }_{5}^{5} S M_{x+10}^{j, I I}
$$

onde, para a região $j$ :

${ }_{5}^{10} S M_{x+10}^{j, d}=$ SM decenal;

${ }_{5}^{5} S M_{x+5}^{j, I}=\mathrm{SM}$ do primeiro quinquênio;

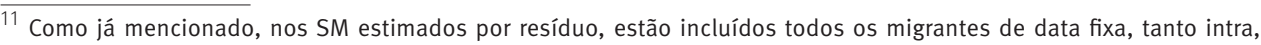
quanto internacionais.
} 
${ }_{5}^{5} \overline{R I S}_{x+5}^{j, I I}=$ razão de sobrevivência estimada, do segundo quinquênio; ${ }_{5}^{5} S M_{x+10}^{j, I I}=$ SM do quinquênio 1995-2000.

De forma análoga, a taxa líquida de migração decenal também não corresponde ao produto das taxas líquidas de migração quinquenais. "Quando as taxas líquidas têm como denominador a população observada ao final do período, a TLM decenal é igual à soma das duas TLM qüinqüenais do período menos o produto delas" (CARVALHO; RIGOTTI, 1998). Assim:

$$
{ }_{5}^{10} T^{1} M_{x+10}^{j, d}={ }_{5}^{5} T L M_{x+5}^{j, I}+{ }_{5}^{5} T L M_{x+10}^{j, I I}-\left({ }_{5}^{5} T_{L} M_{x+5}^{j, I} *{ }_{5}^{5} T L M_{x+10}^{j, I I}\right)
$$

"Quando as taxas líquidas têm como denominador a população esperada ao final do período, a TLM decenal é igual à soma das duas TLM qüinqüenais do período mais o produto delas" (CARVALHO; RIGOTTI, 1998). Então:

$$
{ }_{5}^{10} T L M_{x+10}^{j, d}={ }_{5}^{5} T L M_{x+5}^{j, I}+{ }_{5}^{5} T L M_{x+10}^{j, I I}+\left({ }_{5}^{5} \operatorname{TLM}_{x+5}^{j, I} *{ }_{5}^{5} T L M_{x+10}^{j, I I}\right)
$$

\section{Apresentação das estimativas}

Para realizar as estimativas que se seguem, foi necessário lançar mão de tábuas de mortalidade estaduais, com desagregação por sexo, para a década de 1990, a partir de dados de óbitos provenientes do Sistema de Informação sobre Mortalidade (SIM), do Ministério da Saúde, corrigidos por fatores de correção de sub-registro, estimados por meio das técnicas de Growth Balance e de Preston e Coale (CEDEPLAR, 1999). Já as tabelas de sobrevivência estimadas para o Brasil e suas unidades federativas, também desagregadas por sexo e idade, referentes às décadas de 1970 e 1960, foram tomadas, respectivamente, de Carvalho e Pinheiro (1986) e Carvalho (1978).

Com base nos procedimentos tratados nas seções anteriores, os saldos e as taxas quinquenais líquidas de migração do Brasil e Estados foram estimados segundo idade e sexo, bem como número de emigrantes internacionais do mesmo período. Cabe ressaltar que as estimativas para o total do Brasil resultam da agregação das estimativas dos Estados.

Por fim, a Tabela 1 resume os principais resultados obtidos. As Tabelas 2 a 5 apresentam informações a respeito da população residente, os saldos e as taxas líquidas quinquenais de migração e as estimativas do número de emigrantes internacionais referentes ao quinquênio 1995-2000, para o Brasil e Estados selecionados, segundo grupos de idade e sexo. Neste caso, além do Brasil, apenas serão apresentadas as estimativas para os Estados de São Paulo, Minas Gerais e Paraná, por serem os de maior relevância no que tange às emigrações internacionais.

Deve-se atentar para o fato de que o modelo proposto para estimação do número de emigrantes internacionais, embora logicamente acurado, chega à estimativa do número de emigrantes como o "resíduo dos resíduos", pois, antes, obtém-se, também por resíduo, o saldo migratório quinquenal do Estado. 
Cabe destacar, portanto, que os erros advindos dos próprios dados básicos (erros de declaração de idade e de deficiência de cobertura censitária), assim como os vieses introduzidos no processo de estimação, por meio, por exemplo, dos pressupostos adotados e das funções de mortalidade empregadas, transferem-se, em termos absolutos, para as estimativas obtidas por resíduo.

TABELA 1

Estimativas dos saldos migratórios e emigrantes internacionais, por sexo Estados e Regiões do Brasil - quinquênio 1995-2000

\begin{tabular}{|c|c|c|c|c|c|c|}
\hline \multirow{2}{*}{$\begin{array}{l}\text { Estados e } \\
\text { Regiões }\end{array}$} & \multicolumn{3}{|c|}{ Saldo migratório } & \multicolumn{3}{|c|}{ Emigrantes internacionais } \\
\hline & Homens & Mulheres & Total & Homens & Mulheres & Total \\
\hline Centro-Oeste & 131.785 & 154.839 & 286.624 & 18.728 & 17.395 & 36.122 \\
\hline DF & 7.982 & 23.652 & 31.634 & 3.698 & 4.631 & 8.329 \\
\hline MS & -9.248 & -8.845 & -18.092 & 6.474 & 6.124 & 12.598 \\
\hline MT & 28.749 & 23.153 & 51.902 & 3.169 & 2.408 & 5.577 \\
\hline GO & 104.301 & 116.879 & 221.181 & 5.387 & 4.232 & 9.619 \\
\hline Norte & 41.259 & 19.049 & 60.308 & 8.713 & 8.807 & 17.519 \\
\hline TO & .7 .963 & 4.685 & 12.648 & 467 & 326 & 792 \\
\hline AP & 16.589 & 18.071 & 34.660 & 949 & 459 & 1.408 \\
\hline PA & -26.576 & -39.729 & -66.305 & 2.113 & 2.997 & 5.110 \\
\hline AM & 18.527 & 15.303 & 33.830 & 2.002 & 2.574 & 4.576 \\
\hline RR & 20.058 & 18.890 & 38.948 & 891 & 485 & 1.376 \\
\hline RO & 6.592 & 3.948 & 10.540 & 1.413 & 1.290 & 2.703 \\
\hline$A C$ & -1.893 & -2.120 & -4.014 & 878 & 676 & 1.554 \\
\hline Nordeste & -432.603 & -539.932 & -972.535 & 16.283 & 16.498 & 32.781 \\
\hline MA & -98.947 & -117.835 & -216.781 & 1.087 & 455 & 1.542 \\
\hline $\mathrm{Pl}$ & -28.400 & -41.990 & -70.391 & 534 & 620 & 1.155 \\
\hline CE & -13.615 & -26.356 & -39.970 & 2.445 & 3.133 & 5.577 \\
\hline RN & 3.824 & -586 & 3.238 & 977 & 1.112 & 2.088 \\
\hline PB & -34.855 & -43.425 & -78.280 & 1.493 & 927 & 2.420 \\
\hline PE & -65.533 & -76.551 & -142.084 & 3.538 & 4.324 & 7.862 \\
\hline$A L$ & -41.760 & -46.954 & -88.714 & 651 & 547 & 1.198 \\
\hline SE & -3.880 & -3.610 & -7.490 & 455 & 706 & 1.161 \\
\hline $\mathrm{BA}$ & -149.436 & -182.627 & -332.063 & 5.104 & 4.674 & 9.778 \\
\hline Sul & -45.304 & -27.497 & -72.801 & 50.716 & 50.010 & 100.726 \\
\hline SC & 26.893 & 32.501 & 59.394 & 7.555 & 6.836 & 14.391 \\
\hline PR & -41.619 & -35.801 & -77.420 & 30.471 & 31.903 & 62.374 \\
\hline RS & -30.578 & -24.197 & -54.775 & 12.690 & 11.271 & 23.961 \\
\hline Sudeste & 177.105 & 266.563 & 443.667 & 79.719 & 81.839 & 161.557 \\
\hline ES & 17.374 & 19.021 & 36.395 & 1.744 & 1.462 & 3.206 \\
\hline RJ & 10.956 & 35.990 & 46.946 & 15.282 & 18.291 & 33.573 \\
\hline$M G$ & 11.967 & -2.148 & 9.819 & 15.257 & 11.799 & 27.056 \\
\hline SP & 136.807 & 213.700 & 350.508 & 47.436 & 50.286 & 97.722 \\
\hline Brasil & -127.759 & -126.978 & -254.737 & 174.158 & 174.547 & 348.705 \\
\hline
\end{tabular}

Fonte: IBGE. Censos Demográficos de 1980, 1991 e 2000. 


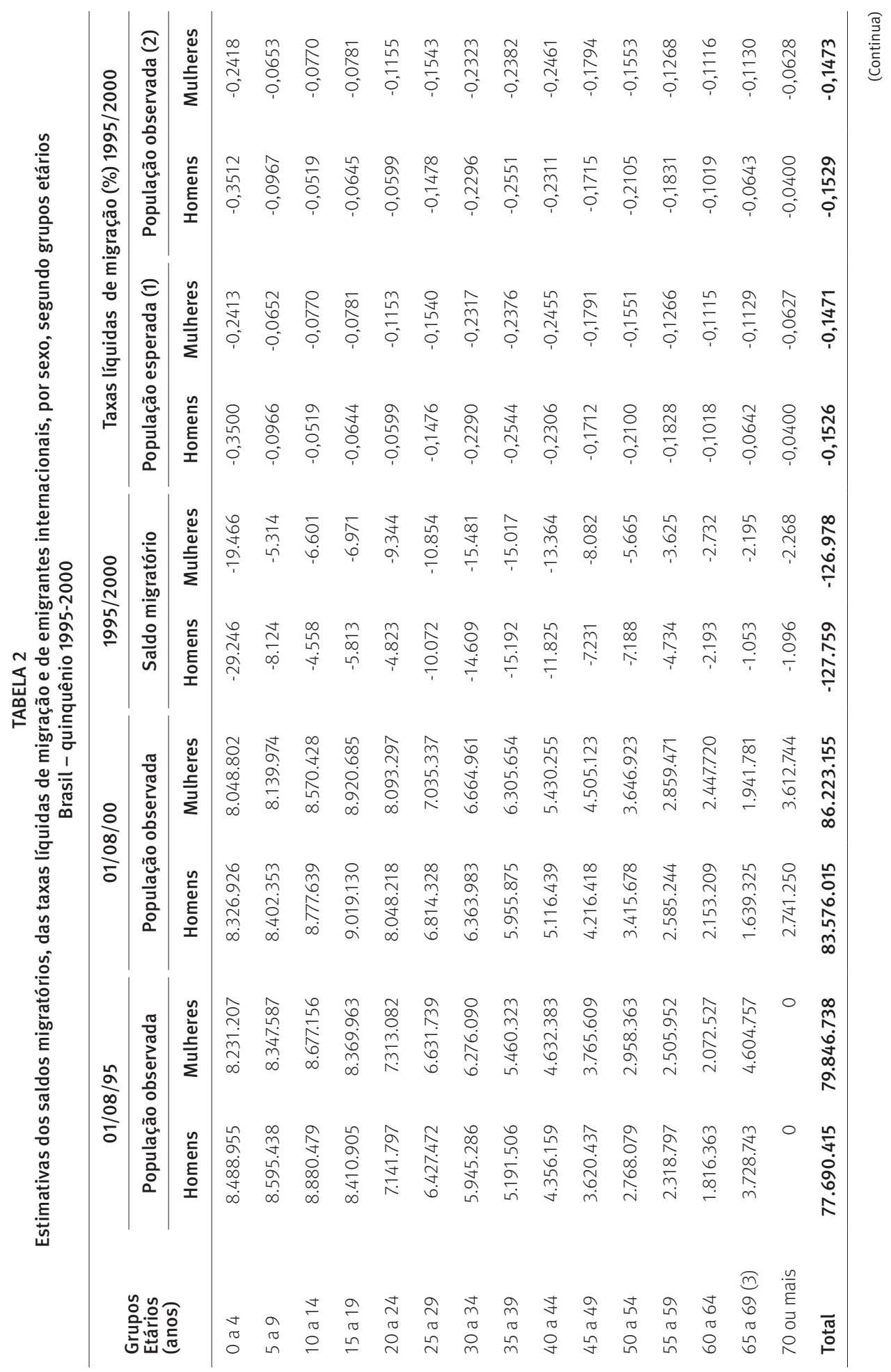




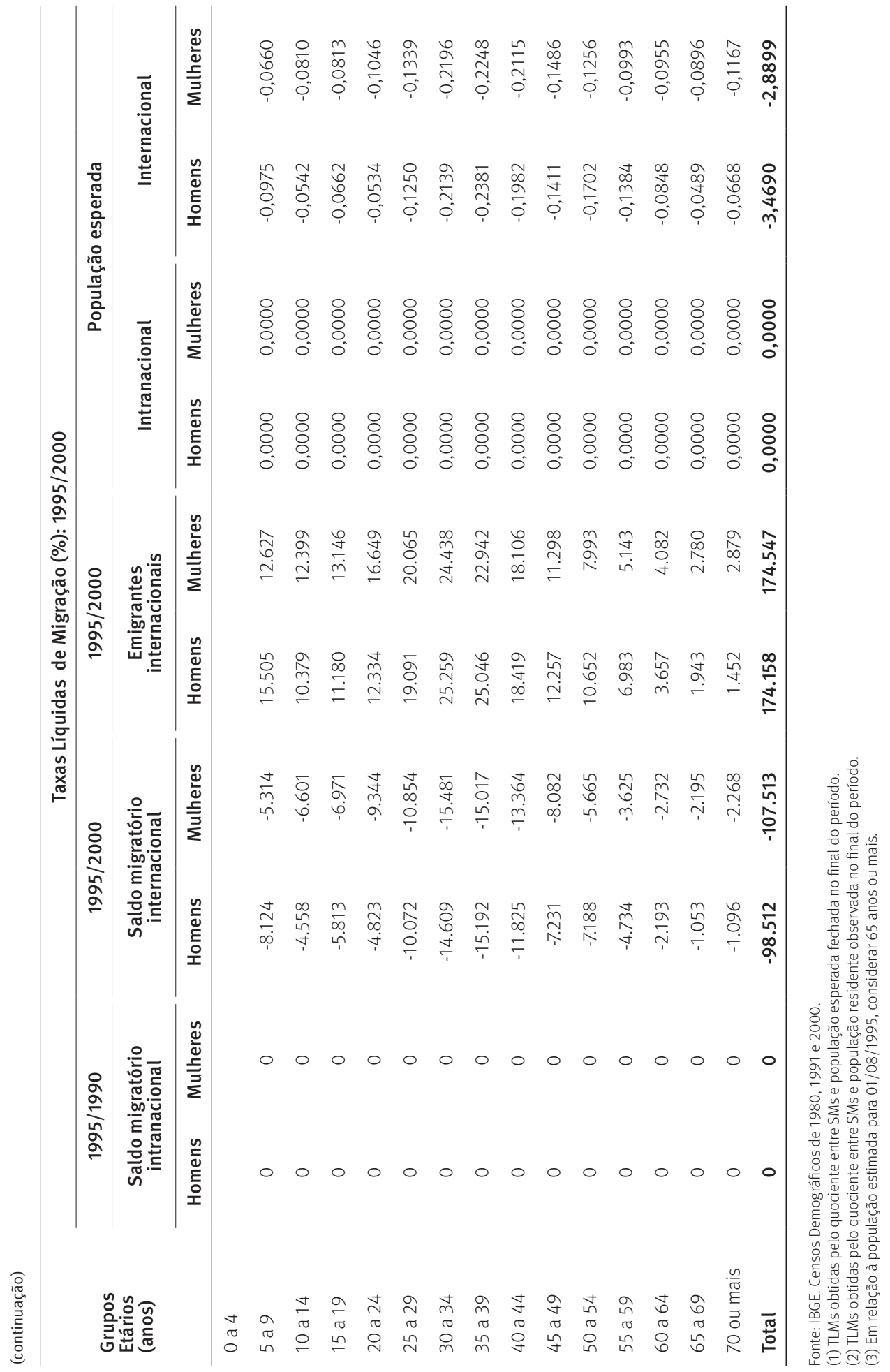




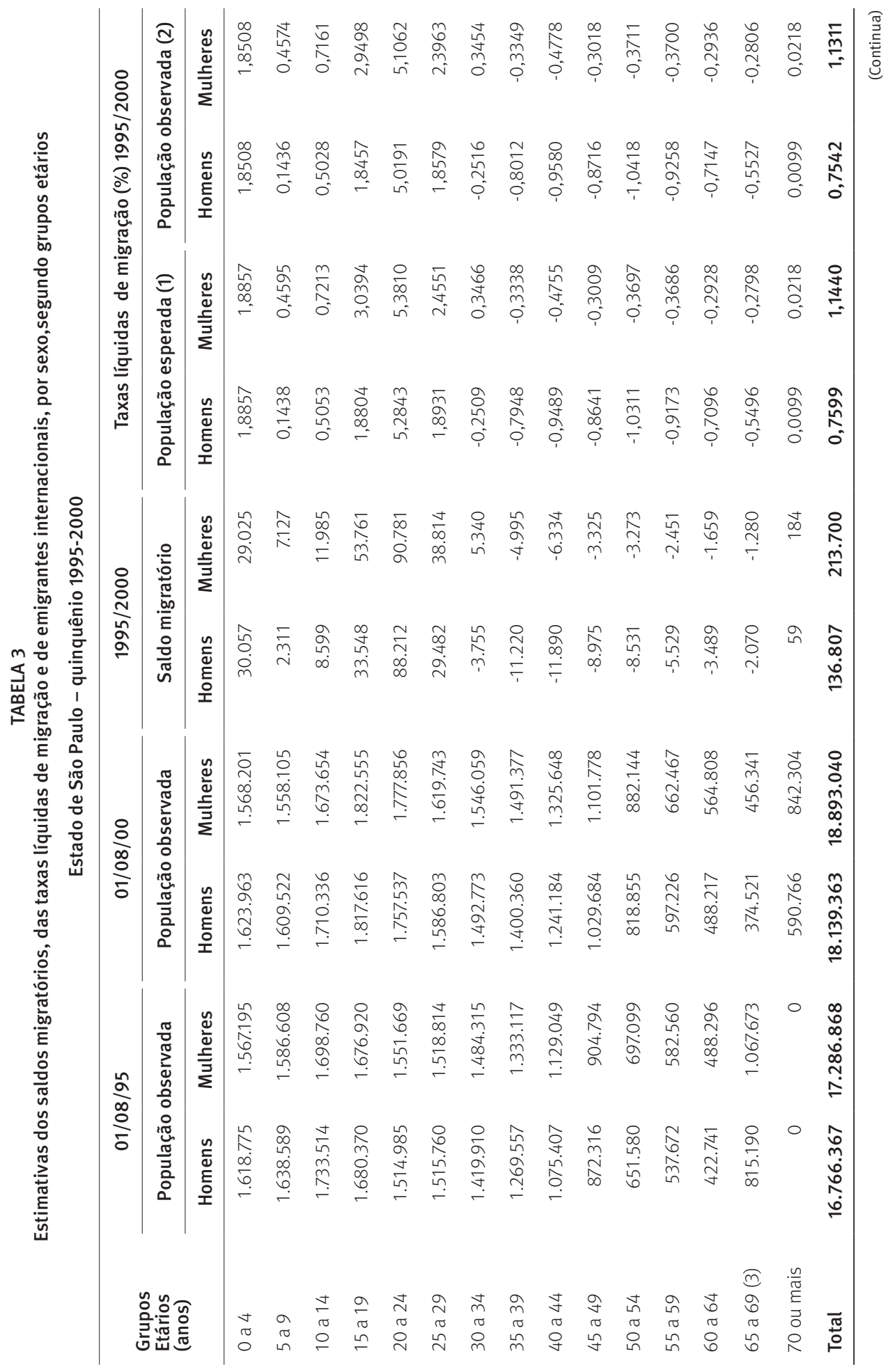




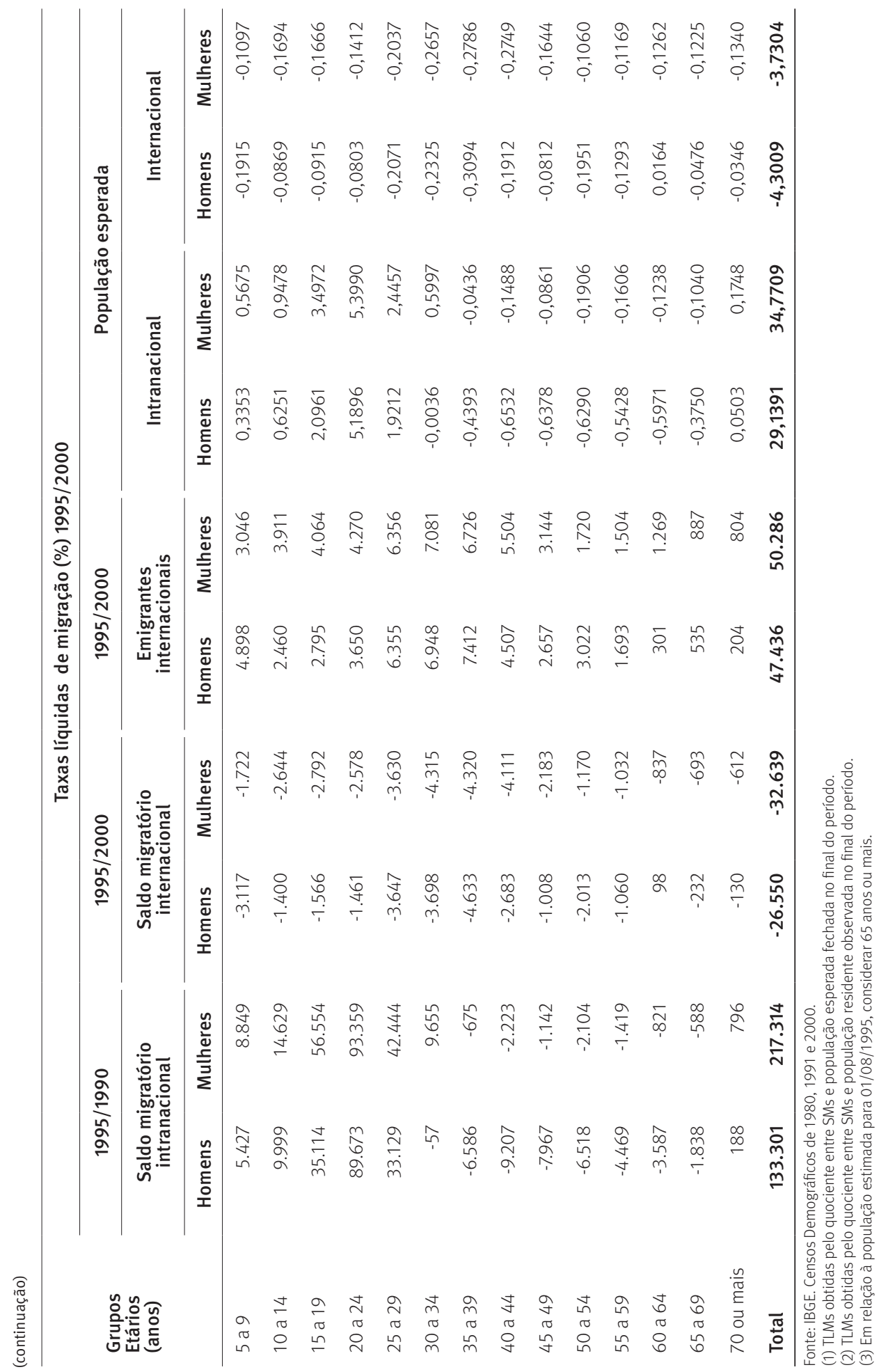




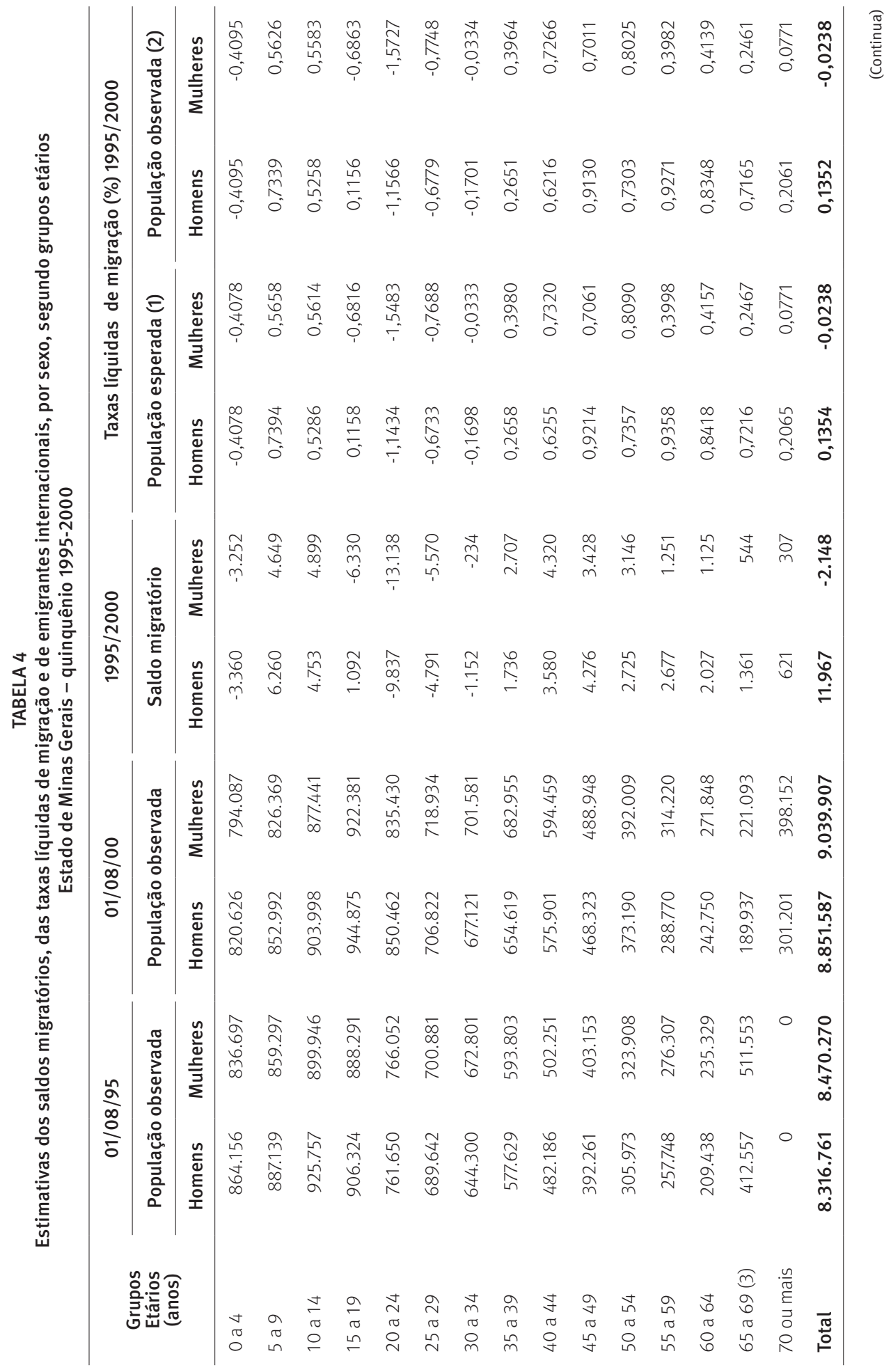




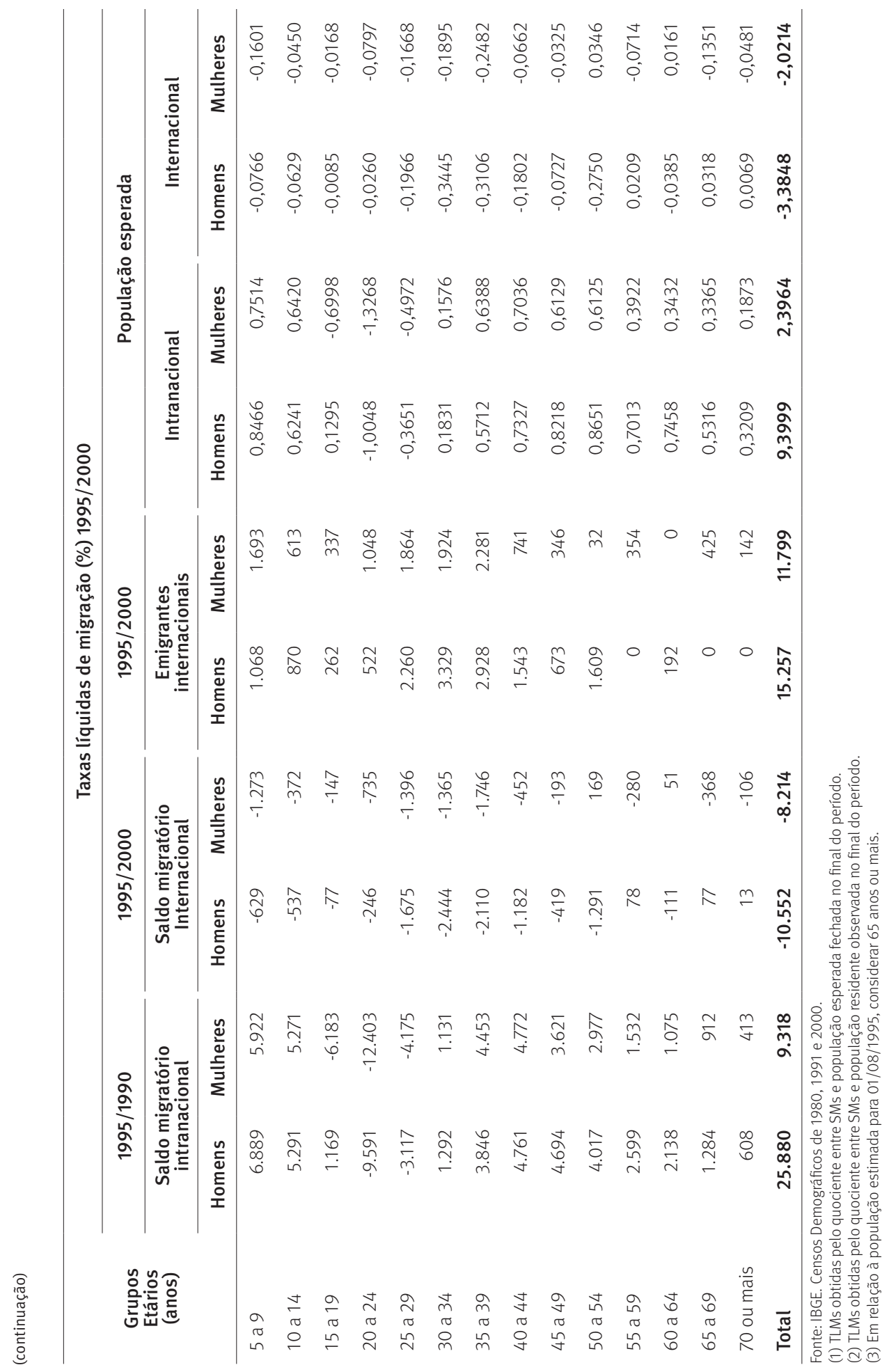




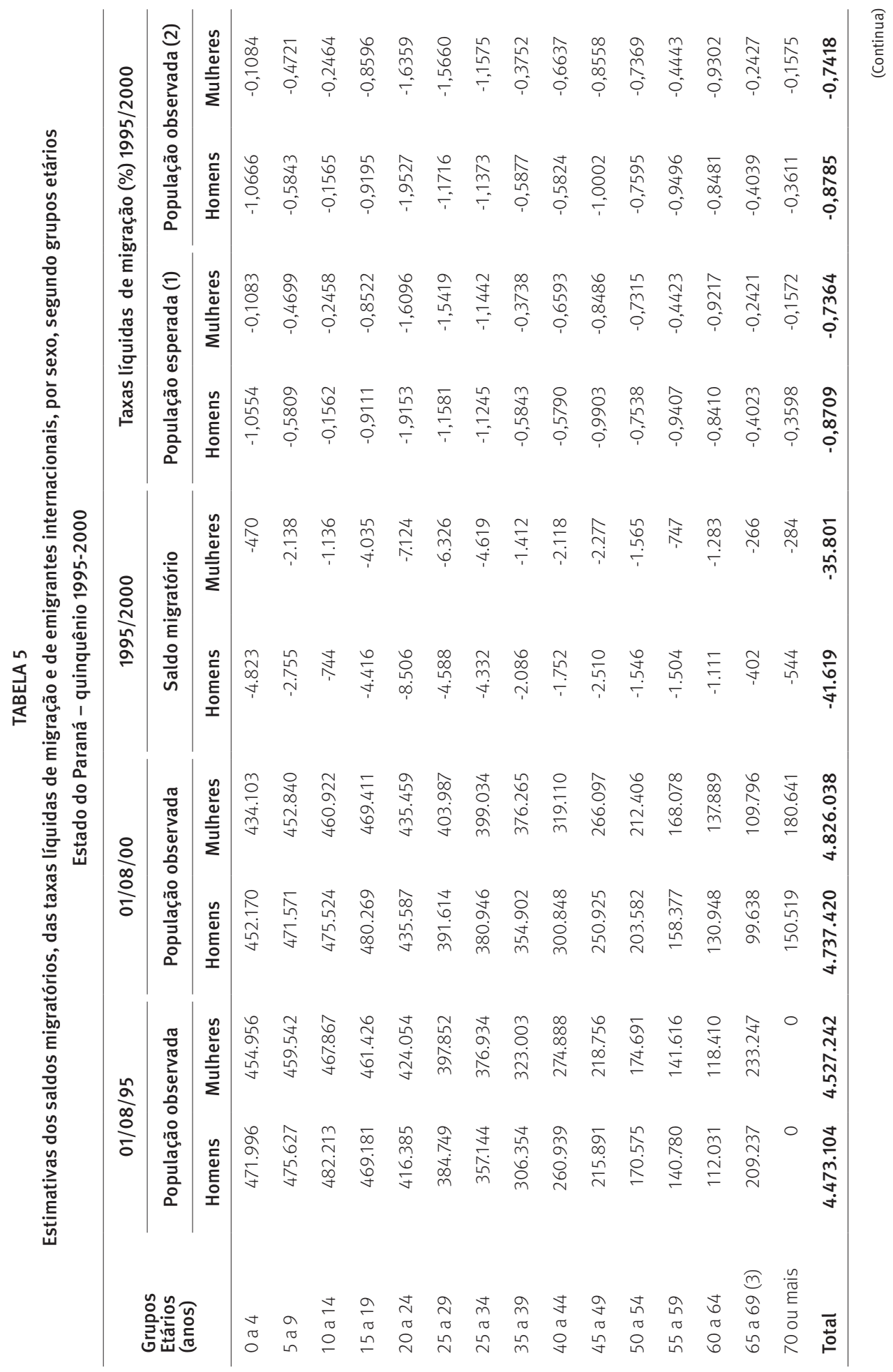




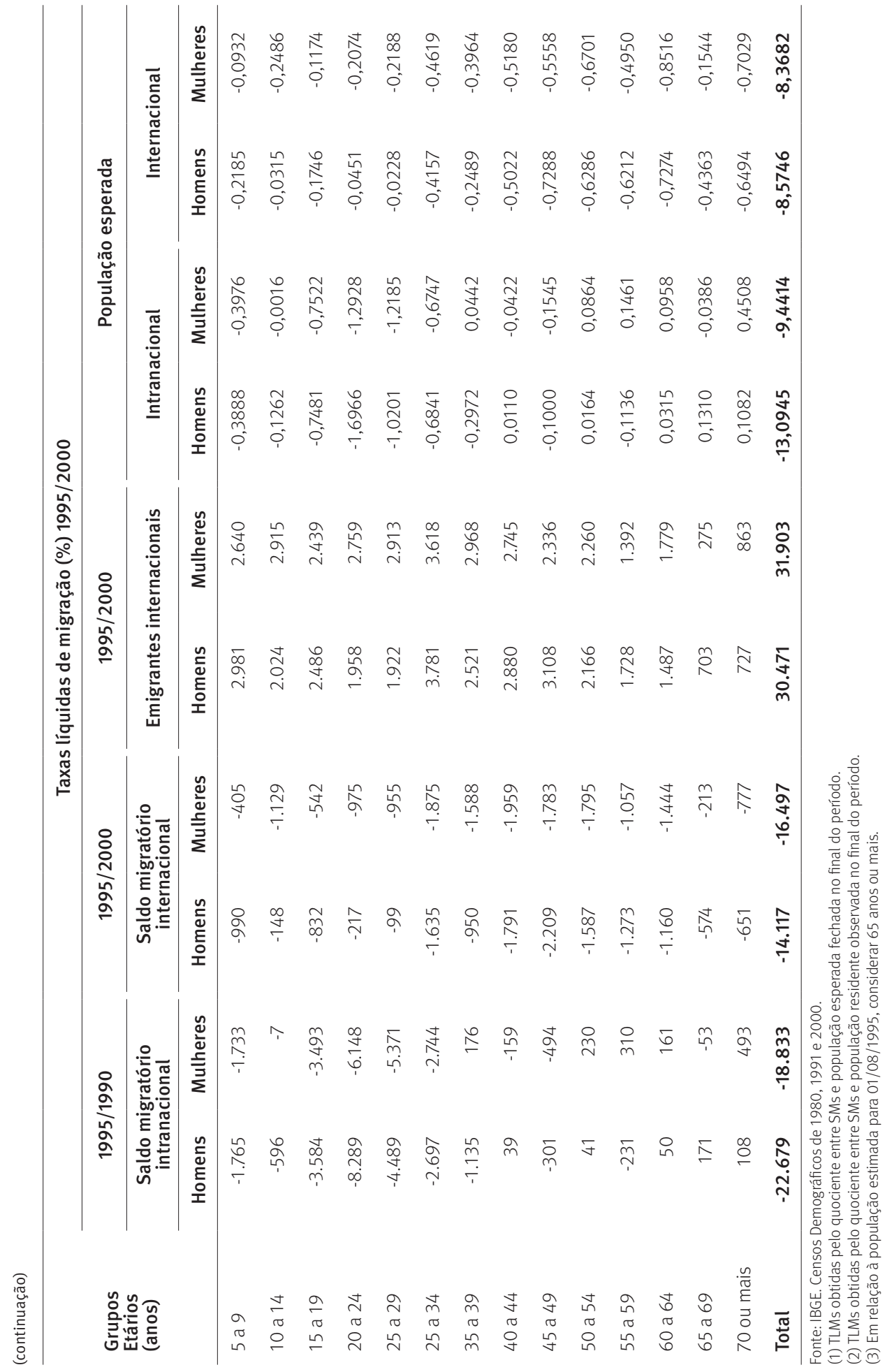




\section{Considerações finais}

Por fim, cabe ressaltar que, tal como é demonstrado por Carvalho et al. (2000), ainda que um modelo de estimativas indiretas de migração seja logicamente acurado, deve sempre ser lembrado que se chega à estimativa do número de emigrantes internacionais como o resíduo dos resíduos, pois para estimá-los obtém-se antes, também por resíduo, o saldo migratório quinquenal total (movimentos intra e internacional) da Unidade da Federação. É sabido que os erros advindos de declaração de idade e de deficiência de cobertura censitária, assim como os vieses introduzidos no processo de estimação - por exemplo, por meio dos pressupostos adotados e das funções de mortalidade empregadas - transferem-se, em termos absolutos, para as estimativas obtidas por esses métodos.

O principal objetivo deste trabalho, entretanto, foi o de compartilhar com a comunidade demográfica alguns avanços que ocorreram no campo da estimação das migrações internacionais no Brasil. Os resultados indicam que houve uma queda acentuada dos fluxos migratórios quando comparamos os dados de décadas anteriores (CARVALHO, 1996; GARCIA, 2005), porém é preciso lembrar que, durante a década de 90, houve expressivos avanços no campo político e econômico no país, o que contribuiu para aumentar a fixação da população brasileira no território nacional - tendência que, acredita-se, continuará nas décadas seguintes.

\section{Referências}

BELTRÃO, K.; CAMARANO, A. A. Cálculo de saldos e taxas líquidas de migração internacional. In: ENCONTRO NACIONAL SOBRE MIGRAÇÃO, 1. Anais... São Paulo: Abep/Ipardes, 1997, p. 291-300.

BILLO, E. J. Excel for chemists: a comprehensive guide. New York: Wiley-VCH, 2001, p. 193-207.

BRITO, F.; GARCIA, R. A.; CARVALHO, J. A. M. As migrações de curto prazo nas regiões metropolitanas: migrantes de etapa única, migrantes de retorno e migrantes de passagem - 1986/1991. In: ENCONTRO NACIONAL DE ESTUDOS POPULACIONAIS, 13. Anais... Belo Horizonte: Abep, 2002.

CARVALHO, J. A. M. Migrações internas: mensuração direta e indireta. In: ENCONTRO NACIONAL DE ESTUDOS POPULACIONAIS, 2. Anais... São Paulo: Abep, 1980.

O saldo dos fluxos migratórios internacionais do Brasil na década de 80 - uma tentativa de estimação. Revista Brasileira de Estudos de População, v. 13, n. 1, p. 3-14, jan./jun. 1996.

CARVALHO, J. A. M.; FERNANDES, F. Estimativas de saldos migratórios e taxas líquidas de migração das unidades da federação e grandes regiões do Brasil, por sexo, idade e setores rural e urbano 1960-1970 e 1970-1980. Belo Horizonte: Cedeplar/UFMG, 1996.

CARVALHO, J. A. M.; CAMPOS, M. B. A. O saldo migratório internacional do Brasil na década de 1990. In: ENCONTRO NACIONAL SOBRE MIGRAÇÃO, 5. Anais... São Paulo: Abep, 2007.

A variação do saldo migratório internacional do Brasil. Estudos Avançados, v. 20, n. 57, 2006 .

CARVALHO, J. A. M.; RIGOTTI, J. I. R. Os dados censitários brasileiros sobre migrações internas: algumas sugestões para análise. Revista Brasileira de Estudos de População, v. 15, n. 2, p. 7-17, jul./dez. 1998.

CARVALHO, J. A. M.; GARCIA, R. A. Estimativas decenais e qüinqüenais de saldos migratórios e taxas líquidas de migração do Brasil, por situação do domicílio, sexo e idade, segundo unidade da 
federação e macrorregião, entre 1960 e 1990, e estimativas de emigrantes internacionais do período 1985/1990. Belo Horizonte: Cedeplar, 2002. Mimeografado.

CARVALHO, J. A. M.; MAGALHÃES, M. V.; GARCIA, R. A.; SOARES, W. Estimativa dos saldos migratórios internacionais e do número de migrantes internacionais das grandes regiões do Brasil: 1986/1991 e 1991/1996. Migrações internacionais contribuições para políticas. Brasília: CNPD, v. 1, 2001, p. 243-252.

Estimação dos emigrantes internacionais de 1986/1991 e de 19991/1996 e dos saldos migratórios qüinqüenais entre 1981 e 1996 do Paraná. In: ENCONTRO ANUAL DA ASSOCIAÇÃO NACIONAL DE PÓS-GRADUAÇÃO E PESQUISA EM CIÊNCIAS SOCIAIS, XXIV. Anais... Petrópolis, 2000.

Minas Gerais e Região de Planejamento VIII - Rio Doce: emigrantes internacionais e saldos migratórios da década de 1980. In: SEMINÁRIO SOBRE A ECONOMIA MINEIRA, VIII. Anais... Belo Horizonte: Cedeplar/UFMG, v. 2, 2000, p. 594-603

Sinuosos caminhos para estimação dos emigrantes internacionais de 1986/1991 e de 1991/1996 e dos saldos migratórios dos qüinqüênios entre 1981 e 1996 das unidades da federação brasileira. In: ENCONTRO NACIONAL DE ESTUDOS POPULACIONAIS, XII. Anais... Caxambu, 2000.

CENTRO DE DESENVOLIMENTO E PLANEJAMENTO REGIONAL. Projeção populacional das Unidades da Federação, Brasil, por sexo e grupos qüinqüenais de idades, 1990-2020. Belo Horizonte: Cedeplar, 1999. Mimeografado.

DUCHESNE, L. Proyecciones de poblacíon por sexo y edad para áreas intermedias y menores - método "relación de cohortes". In: SUBNACIONALES DE POPULACION. Dane/Celade, 1989.

GARCIA, R. A. Estimativas dos emigrantes internacionais do Brasil do período 1995/2000. In: ENCONTRO NACIONAL DE ESTUDOS POPULACIONAIS, XVII. Anais... Caxambu: Abep, 2010.

The estimates of the Brazilian international net migration and the Brazilian emigrants, based on the method of inter-census survival ratio (ISR). In: XXVth IUSSP INTERNATIONAL POPULATION CONFERENCE. Abstracts Book. Tours, 2005.

GARCIA, R. A.; SOARES, W. Estimativa dos SM, das TLM e dos emigrantes internacionais da Macrorregião VIII - Rio Doce. In: ENCONTRO NACIONAL SOBRE MIGRAÇÃO, 2. Anais... São Paulo: Abep, 2000.

MAGALHÃES, M. V. O Paraná e suas regiões nas décadas recentes: as migrações que também migram. Tese (Doutorado). Belo Horizonte: Cedeplar/UFMG, 2003.

RIBIERO, J. L. Estimativa da migração de retorno e de alguns de seus efeitos demográficos indiretos no Nordeste brasileiro. Tese (Doutorado). Belo Horizonte: Cedeplar/UFMG, 1997.

RIGOTTI, J. I. R. Técnicas de mensuração das migrações, a partir de dados censitários: aplicação aos casos de Minas Gerais e São Paulo. Tese (Doutorado). Belo Horizonte: Cedeplar/UFMG, 1999.

SOARES, V. Da metáfora à substância: redes sociais, redes migratórias e migração nacional e internacional em Valadares e Ipatinga. Tese (Doutorado). Belo Horizonte: Cedeplar/UFMG, 2002.

WALDVOLGEL, B. C. Técnicas de projeção populacional para o planejamento regional. Belo Horizonte: Cedeplar/UFMG, 1977. 


\begin{abstract}
Estimates of international migrants leaving Brazil between 1995 and 2000: an application of the intercensal survival method

Due to the lack of data on demographic movements in space and time, demographers and scholars of the population have long resorted to indirect methods for measuring net migration. The most recent Brazilian Demographic Censuses contain a considerable amount of data on population movements that can provide direct estimates of migratory flows. In addition, data not directly related to migration, but handled through the application of indirect techniques, provide estimates of net migration. More recently a combination of direct and indirect techniques has made it possible to estimate international migration flows. This question represents a methodological challenge and represents an opportunity to understand important aspects of the dynamics of migration in Brazil. Few studies, however, have dealt with the development and improvement of methods and techniques aimed at estimating analytical categories such as international emigration. The main objective of this paper is therefore to provide estimates of international emigration of Brazilians by sex, age and state during the second half of the 1990s, by applying the Census Survival Ratio Method.
\end{abstract}

Keywords: International migration. Indirect migration methods. Brazil.

\title{
Resumen
}

\section{Estimaciones de los emigrantes internacionales de Brasil entre 1995 y 2000: una aplicación del método de las razones intercensales de supervivencia}

Dada la ausencia de datos sobre movimientos poblacionales en el espacio y en el tiempo, hace mucho que los demógrafos y estudiosos de población utilizan técnicas indirectas para la mensuración de saldos migratorios. Los últimos censos demográficos brasileños contienen un notable conjunto de datos sobre movimientos poblacionales que, si adecuadamente trabajados, pueden proporcionar estimaciones sobre importantes aspectos de los flujos migratorios. Por otro lado, datos no directamente vinculados a la migración, manipulados a partir de técnicas indirectas, permiten llegar a la estimación de saldos migratorios. La generación de estimaciones de flujos migratorios internos y, más recientemente, también de los internacionales, por medio de la combinación de técnicas directas e indirectas, representa un desafío metodológico que viene siendo enfrentado por algunos demógrafos dedicados a los estudios de migración. Sin embargo, pocos estudios se han destinado a desarrollar y a perfeccionar métodos y técnicas direccionados a la estimación de categorías analíticas, tales como saldos migratorios intercensales, migración de retorno, migración por etapas, migración de paso y emigración internacional. Por lo tanto, el principal objetivo de este trabajo es ofrecer estimaciones de la emigración internacional de brasileños por sexo, edad y unidades de la federación, referentes a la segunda mitad de la última década del siglo por medio de la técnica de las Razones de Supervivencia Intercensales (RSI).

Palabras clave: Migración internacional. Técnicas indirectas de migración. Brasil.

Recebido para publicação em 25/08/2011

Aceito para publicação em 01/12/2011 